\title{
Is Exercise a Solution for Every Individual Living with Chronic Conditions?
}

\author{
Danielle R Bouchard, Travis Hrubeniuk ${ }^{1}$ and Martin Sénéchal ${ }^{1 *}$ \\ University of New Brunswick, Faculty of Kinesiology Fredericton, Cardiometabolic, Exercise, and Lifestyles Laboratory, Canada
}

Submission: June 13, 2017; Published: June 27, 2017

*Corresponding author: Martin Sénéchal, University of New Brunswick, Faculty of Kinesiology Fredericton, Cardiometabolic, Exercise, and Lifestyles Laboratory, Canada, Tel: (506) 451-6889; Fax: 506-453-3511; Email: martin.Senechal@unb.ca

\section{Opinion}

The simple answer is probably 'it depends'! The outcomes experienced as a result of exercise varies depending on the expected outcome, the chronic condition, and how exercise is defined. In past decades, the public health messages have shouted from every rooftop that exercise is a corner stone to manage chronic conditions. We would argue that while this argument is correct from a general health perspective, however for some individuals their odds of achieving their health goals through engagement in exercise may not be as glorious as expected. In other words, a patient might experience some of the reported benefits of engagement in exercise, such as a reduction in blood pressure and improvement in glycemic control, but experience a lack of improvement in other areas, such as not returning to their desired weight.

Most agencies that provide recommendations for Type2 diabetes (T2D) prevention and treatment highlight regular exercise as one of the most important behavioral changes individuals with T2D can make to improve their condition. Typically, it is promoted that such improvements include enhanced glycemic control and protection against the onset of diabetes-related complications [1]. One such agency includes Diabetes Canada, whore commends 150 minutes of moderateto-vigorous aerobic activity in addition to two sessions of resistance exercise per week [2]. Similarly, the American College of Sports Medicine (ACSM) calls for obese individuals to perform a minimum of 150 minutes of moderate-to-vigorous intensity to expect modest weight loss [3]. While some health benefits associated with exercise are undeniable for the majority of the population, predicting the specific outcomes experienced has proven difficult [4]. Typically, improvements in cardiorespiratory fitness (CRF) will be the primary trigger for metabolic and functional improvements. However, despite seeming lyubiquitous reports of the benefits associated with exercise, numerous findings exist indicating that some individuals do not improve their CRF following an intervention [4-6]. These individuals have previously been termed 'non-responders'. That said, our group investigated youth at risk of T2D and found a significant variability in metabolic response across changes in CRF. In other words, youth who change their CRF over 6-month intervention are the one who increase their health [7]. Recently alterative studies have attempted to eradicate the presence of exercise non-response through the modification of exercise parameters. For example, Ross et al. [8]. Investigated the effect of various combinations of walking-based activity volume and intensity with 121 obese participants over 24 weeks. The authors found that increasing exercise volume and intensity eliminated all non-responders based on CRF metrics, whereas lower volumes and intensities could not. Additionally, Montero \& Lund [9] randomized participants into one of five exercise programs, each differing in the volume of exercise completed per week. The authors reported that those completing the highest volume of exercise had no trace of non-response. Meanwhile, groups completing lower volumes of exercise displayed a multitude of non-responders. The non-responders then progressed through a second training period with an increased volume, and found that doing so disposed of all non-response. The findings from these authors provide evidence that non-response to exercise may not truly exist, and that some individuals require higher exercise volumes or intensities to achieve desired health outcomes. Similar to the currently prevailing mindset, studies completed by Sénéchal et al. [10] and Church et al. [11]. Reported large heterogeneity in their participant abilities to enhance glycemic control in response to exercise programs. The rate of nonresponse interms of the ability of exercise to benefit those with T2D has been estimated to be about 20\% [12].

Moreover, are view completed by Bouchard et al. [13]. Found that some experience adverse metabolic effects to engagement in exercise, including are ported $8.3 \%$ of participants who 


\section{Current Research in Diabetes \& Obesity Journal}

increased their fasting insulin concentrations, suggesting a decrease in insulin sensitivity or glucose metabolism efficiency. As evidence continues to mount showing that adaptations to current exercise programs, potentially through increases in the intensity and duration recommended by current exercise guidelines provided through agencies such as Diabetes Canada and ACSM, it may be time to reexamine the way in which exercise is prescribed to individuals. Alternatively, research should start investigating alternative strategies and combinations of exercise and lifestyle modifications to assist those who are currently described as non-responders.

One such strategy worth investigating may the expansion of the current recommendation of 'exercise' for a set time each week, to observing how incorporating physical activity throughout a full day, every day can contribute the treatment of chronic conditions. Focusing efforts exclusively on moderateto-vigorous aerobic exercise that accounts for less than $5 \%$ of a full day [14] limits our understanding of how exercise and physical activity are potentially associated with metabolic and functional health benefits. Perhaps a comprehensive approach including all activities performed in a day, despite their mode or intensity, should be evaluated to truly understand the role of physical activity on metabolic and functional health. Chaput et al. suggested that the combined effects of different intensities and modes of activities extend beyond the individual contributions of each on health [14]. This was supported by other subsequent evaluations $[15,16]$. In addition, a large body of literature suggests that sedentary time must be considered to evaluate the importance of physical activities for health [17-21]. Recent epidemiological studies have shown that despite adherence to the physical activity guidelines, the risk of mortality and onset of cardiovascular disease increases with more than six hours of sitting per day $[22,23]$. However, a meta-analysis of one million participants completed by Ekelundet al. found that a high level of moderate intensity physical activity ( $>60$ minutes per day) seems to eliminate the increased mortality risk associated with high volumes of sitting [24]. The importance of using a comprehensive approach to evaluate the association between total daily physical activity and health has been proposed in the past decade and has proved to be quite useful, especially in children $[14,25,26]$. Different modes and intensities of physical activity needs to be studied to understand the ideal combination that should be targeted to maximize metabolic and functional health benefits in adults.

Based on the literature presented above, it may be possible that adapting the approach to exercise and physical activity may lead to an increased volume of patients responding favorably, thus enhancing the number of those who identifying as 'responders'. The benefits of modifying the treatment in terms of intensity, mode, volume, or by adopting a more comprehensive, physical activity lifestyle approach has shown great promise thus far, but additional research remains necessary. While previous examination indicates that alterations to an unsuccessful exercise training program may convert previous non-responders to responders, these studies focused mostly on fitness-based outcomes. Understanding the ability of enhanced training programs for those labeled as non-responders and understanding mechanism by which chronic diseases improvement is observed could re-establish exercise as a treatment option for those living with conditions such as T2D or obesity, there by positively impacting the quality of life of additional patients. Based on the current literature, there is a need to identify these nonresponding patients, and work with them to determine the most effective alterations to currently offered programs to help them respond. This could include a more individualized increase intensity, duration, mode of activities, a combination of these variables, or a broader approach inclusive of all daily physical activity outcomes.

\section{References}

1. Canadian Society for Exercise Physiology (2013) Canadian Society for Exercise Physiology - Physical Activity Training for Health (CSEPPATH).

2. Canadian Diabetes Association (2003) Diabetes in Ontario: An ICES Practice Atlas. 314 (Institue for Clinical Evaluative Sciences, 2003).

3. Donnelly JE, Blair SN, Jakicic JM, Manore MM, Rankin JW, et al. (2009) American College of Sports Medicine Position Stand. Appropriate Physical Activity Intervention Strategies for Weight Loss and Prevention of Weight Regain for Adults. Med Sci Sports Exerc 41(2): 459-471.

4. Skinner JS, Jaskólski A, Jaskólska A, Krasnoff J, Gagnon J, et al. (1985) Age, sex, race, initial fitness, and response to training: the HERITAGE Family Study. J Appl Physiol 90(5): 1770-1776.

5. Sisson SB, Katzmarzyk PT, Earnest CP, Bouchard C, Blair SN, et al. (2009) Volume of Exercise and Fitness Non-Response in Sedentary, Post-Menopausal Women. Med Sci Sports Exerc 41(3): 539-545.

6. Gurd BJ, Giles MD, Bonafiglia JT, Raleigh JP, Boyd JC, et al. (2016) Incidence of nonresponse and individual patterns of response following sprint interval training. Appl Physiol Nutr Metab 41(3): 229234.

7. Sénéchal M, Rempel M, Duhamel TA, MacIntosh AC, Hay J, et al. (2015) Fitness is a determinant of the metabolic response to endurance training in adolescents at risk of type 2 diabetes mellitus. Obesity 23(4): 823-832.

8. Ross R, de Lannoy L, Stotz PJ (2015) Separate Effects of Intensity and Amount of Exercise on Interindividual Cardiorespiratory Fitness Response. Mayo Clin Proc 90(11): 1506-1514.

9. Montero D, Lundby C (2017) Refuting the myth of non-response to exercise training: 'non-responders' do respond to higher dose of training. J Physiol 595(11): 3377-3387.

10. Sénéchal M , Swift DL, Johannsen NM, Blair SN, Earnest CP, et al. (2013) Changes in Body Fat Distribution and Fitness Are Associated With Changes in Hemoglobin A1c After 9 Months of Exercise Training. Diabetes Care 36(9): 2843-2849.

11. Church TS, Blair SN, Cocreham S, Johannsen N, Johnson W, et al. (2010) Effects of Aerobic and Resistance Training on Hemoglobin A1c Levels in Patients With Type 2 Diabetes: A Randomized Controlled Trial. JAMA 304(20): 2253-2262.

12. Stephens NA, Sparks LM (2015) Resistance to the Beneficial Effects of Exercise in Type 2 Diabetes: Are Some Individuals Programmed to Fail? J Clin Endocrinol Metab 100(1): 43-52. 


\section{Current Research in Diabetes \& Obesity Journal}

13. Bouchard C, Blair SN, Church TS, Earnest CP, Hagberg JM, et al. (2012) Adverse Metabolic Response to Regular Exercise: Is It a Rare or Common Occurrence? PLoS One 7(5): e37887.

14. Chaput JP, Carson V, Gray CE, Tremblay MS (2014) Importance of All Movement Behaviors in a 24 Hour Period for Overall Health. Int J Environ Res Public Health 11(12): 12575-12581.

15. Chastin SF, Palarea-Albaladejo J, Dontje ML, Skelton DA (2015) Combined Effects of Time Spent in Physical Activity, Sedentary Behaviors and Sleep on Obesity and Cardio-Metabolic Health Markers: A Novel Compositional Data Analysis Approach. PLoS One 100 e0139984.

16. Thompson D, Peacock O, Western M, Batterham AM (2015) Multidimensional Physical Activity: An Opportunity, Not a Problem. Exerc Sport Sci 43(2): 67-74

17. Dunstan DW, Thorp AA, Healy GN (2011) Prolonged sitting: is it a distinct coronary heart disease risk factor? Curr Opin Cardiol 26(5) 412-419.

18. Hamilton MT, Hamilton DG, Zderic TW (2007) Role of Low Energy Expenditure and Sitting in Obesity, Metabolic Syndrome, Type 2 Diabetes, and Cardiovascular Disease. Diabetes 56(11): 2655-2667.

19. Katzmarzyk PT, Janssen I (2004) The Economic Costs Associated With Physical Inactivity and Obesity in Canada: An Update. Can J App Physiol 29(1): 90-115.
20. Owen N, Healy GN, Matthews CE, Dunstan DW (2010) Too Much Sitting The Population Health Science of Sedentary Behavior. Exerc Sport Sci Rev 38(3): 105-113.

21. Shiyovich A, Shlyakhover V, Katz A (2013) Sitting and cardiovascular morbidity and mortality. Harefuah 152(1): 43-48, 58, 57.

22. Katzmarzyk PT, Church TS, Craig CL, Bouchard C (2009) Sitting Time and Mortality from All Causes, Cardiovascular Disease, and Cancer. Med Sci Sports Exerc 41(5): 998-1005

23. Patel AV, Bernstein L, Deka A, Feigelson HS, Campbell PT, et al. (2010) Leisure Time Spent Sitting in Relation to Total Mortality in a Prospective Cohort of US Adults. Am J Epidemiol 172(4): 419-429.

24. Ekelund U, Jostein Steene-Johannessen, Wendy J Brown, Morten Wang Fagerland, Neville Owen, et al. (2016) Does physical activity attenuate, or even eliminate, the detrimental association of sitting time with mortality? A harmonised meta-analysis of data from more than 1 million men and women. The Lancet 388(10051): 1302-1310.

25. Saunders TJ, Gray CE, Poitras VJ, Chaput JP, Janssen I, et al. (2016) Combinations of physical activity, sedentary behaviour and sleep: relationships with health indicators in school-aged children and youth. Appl Physiol Nutr Metab 41(6 Suppl 3): S283-S293.

26. Tremblay MS, Carson V, Chaput JP (2016) Introduction to the Canadian 24-Hour Movement Guidelines for Children and Youth: An Integration of Physical Activity, Sedentary Behaviour, and Sleep. Appl Physiol Nutr Metab 41: 1-17.

\section{Your next submission with Juniper Publishers will reach you the below assets}

- Quality Editorial service

- Swift Peer Review

- Reprints availability

- E-prints Service

- Manuscript Podcast for convenient understanding

- Global attainment for your research

- Manuscript accessibility in different formats ( Pdf, E-pub, Full Text, Audio)

- Unceasing customer service

Track the below URL for one-step submission https://juniperpublishers.com/online-submission.php 